\title{
Primary Intraosseous Synovial Sarcoma in the Mandible
}

\author{
Lucas Novaes Teixeira $\mathbb{D}^{\mathbb{D}},{ }^{1}$ Eduardo Zambaldi da Cruz $\mathbb{D}^{1},{ }^{1}$ Ana Cláudia Garcia Rosa $\mathbb{D},{ }^{1,2}$ \\ Anderson Abdo Rodrigues, ${ }^{2}$ Fabrício Passador-Santos $\mathbb{D}^{1},{ }^{1}$ Vera Cavalcanti de Araújo $\mathbb{D}^{1}$, \\ and Andresa Borges Soares ${ }^{1}{ }^{1}$
}

\author{
${ }^{1}$ Faculdade São Leopoldo Mandic, Rua José Rocha Junqueira 13, Swift, 13045-755 Campinas, SP, Brazil \\ ${ }^{2}$ School of Medicine, Federal University of Tocantins, Avenida NS-15, Quadra 109, Norte, S/n-Plano Diretor Norte, \\ Palmas TO 77001-090, Brazil
}

Correspondence should be addressed to Lucas Novaes Teixeira; novaesrp@yahoo.com.br

Received 16 March 2021; Revised 20 October 2021; Accepted 26 October 2021; Published 28 November 2021

Academic Editor: Raffaele Palmirotta

\begin{abstract}
Copyright ( 2021 Lucas Novaes Teixeira et al. This is an open access article distributed under the Creative Commons Attribution License, which permits unrestricted use, distribution, and reproduction in any medium, provided the original work is properly cited.
\end{abstract}

\begin{abstract}
Synovial sarcoma (SS) is a rare malignant mesenchymal tumor that mainly occurs in body extremities, being uncommon in the head and neck region. In the present study, we described a case of primary intraosseous SS arising in the mandible of a 22 year-old young male. The patient reported a painful swelling on the left side of the mandible for the last 7 months. Imaging exams showed the presence of an expansive and multilocular radiolucent lesion, extending from the left condyle to the mandibular body. The clinic diagnostic hypotheses were ameloblastoma or malignant neoplasm. Histologically, the lesion was characterized by a proliferation of spindle cells exhibiting vesicular nuclei and evident nucleolus. Neoplastic cells were positive for AE1/AE3, cytokeratin 7, vimentin, CD-99, and TLE-1 and negative for CD-34, S-100, SMA, and HHF-35. A combination of clinical, histologic, and immunohistochemical characteristics supported the diagnosis of SS. The patient was referred for treatment, and preoperative exams did not reveal any other tumor foci in the body of the patient. The final diagnosis was of a primary intraosseous SS of the mandible.
\end{abstract}

\section{Introduction}

Synovial sarcoma (SS) is a rare neoplasm accounting for up $10 \%$ of all sarcomas [1-3]. The term SS was first proposed by Knox in 1936 due to the similarity of this neoplasm with normal synovial tissues [4]. Despite the name, this neoplasm does not originate from the synovium or synovial structures. In fact, some studies have suggested that SS can be derived from undifferentiated cells, neural crest stem cells, or pluripotent mesenchymal cells and may arise in any part of the human body [5-8]. Histologically, SS can be classified into biphasic, monophasic, and poorly differentiated. Biphasic SS is composed of spindle cells and epithelial cells, the latter forming nests and glandular structures. Monophasic SS is characterized by highly cellular solid sheets of small spindle cells. Poorly differentiated SS is composed mainly of solid sheets of rounded cells [9-11].
SS usually occurs in extremities, being very rare in the head and neck region [12-14]. In such place, SS often arises in the hypopharynx and parapharyngeal spaces, mainly in the paravertebral connective tissue and being less common in the larynx [15]. In oral cavity, the first case of SS was reported in the base of the tongue of a 23-year-old female [16]. Besides the tongue [17-19], SS can arise in other oral structures such as the buccal mucosa [20,21], soft and hard palate [22-24], gingiva [25], retromolar area [26], and the floor of the mouth $[27,28]$. The involvement of the jaws by SS is extremely rare, and only 23 cases of primary intraosseous SS have been reported in the literature [29]. In this region, SS is usually diagnosed in young female patients, with the mandible and maxilla being equally affected [29]. This article was aimed at reporting a new case of primary intraosseous SS arising in the mandible of a young male patient. 


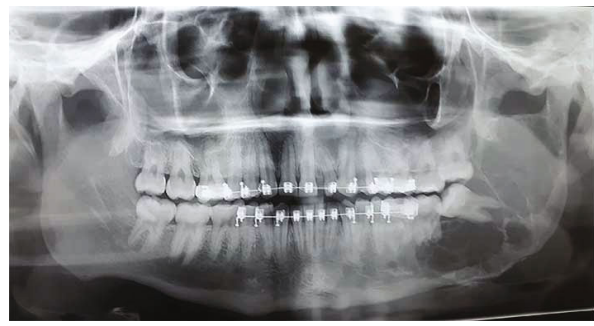

(a)

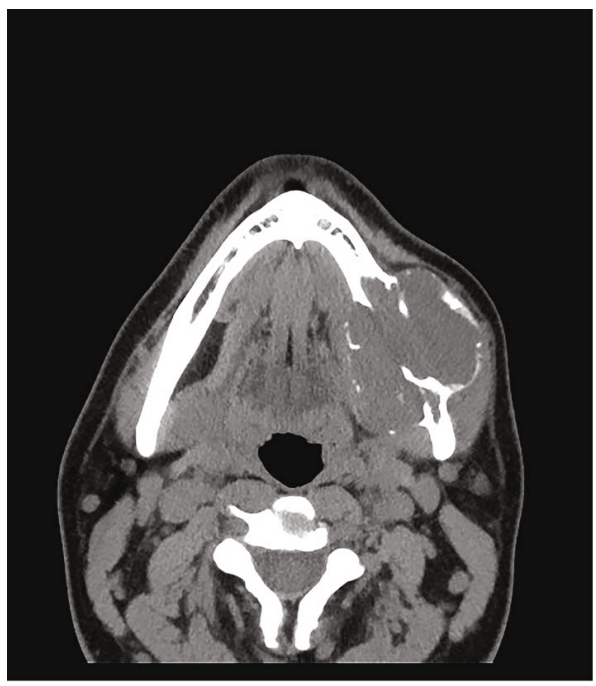

(c)

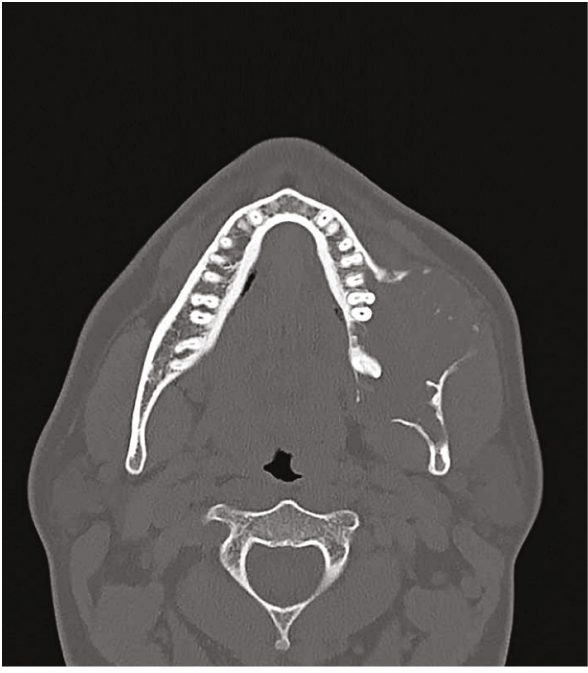

(b)

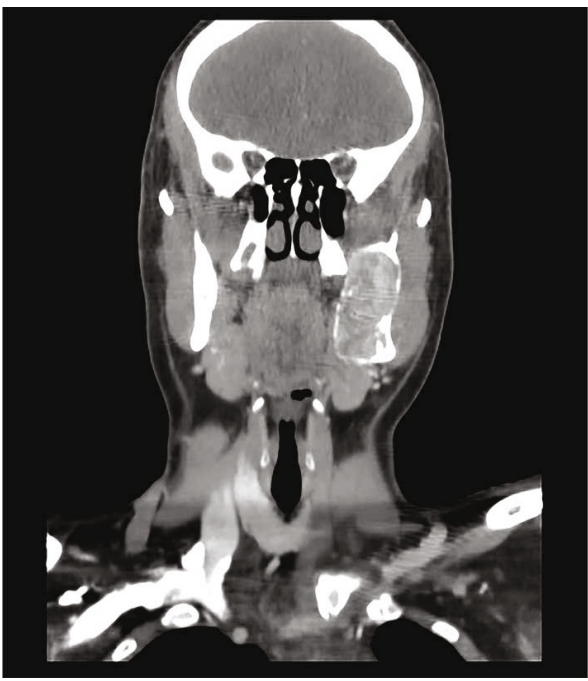

(d)

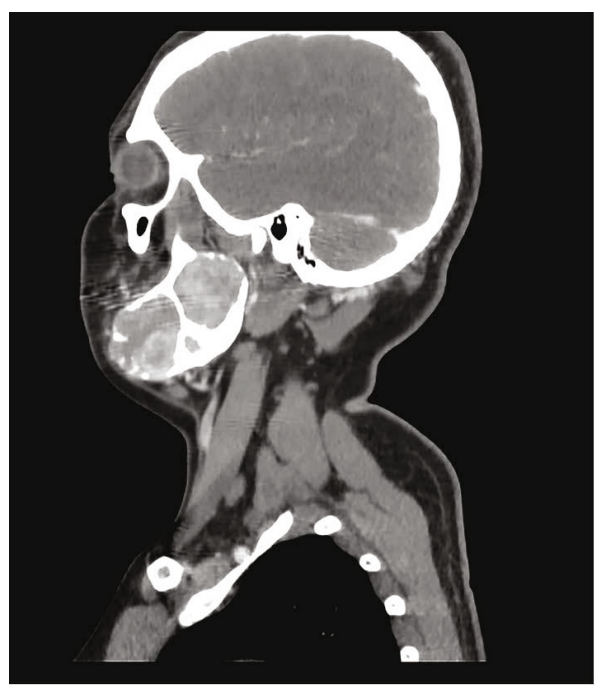

(e)

FIgURe 1: Panoramic radiograph revealed a multilocular radiolucency in the body and ramus of the mandible (a). Computed axial tomography revealed a large hypodense lesion exhibiting cortical bone destruction (b-e). 


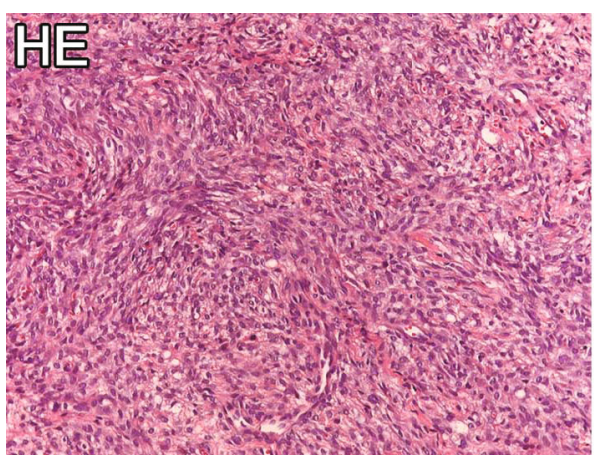

(a)

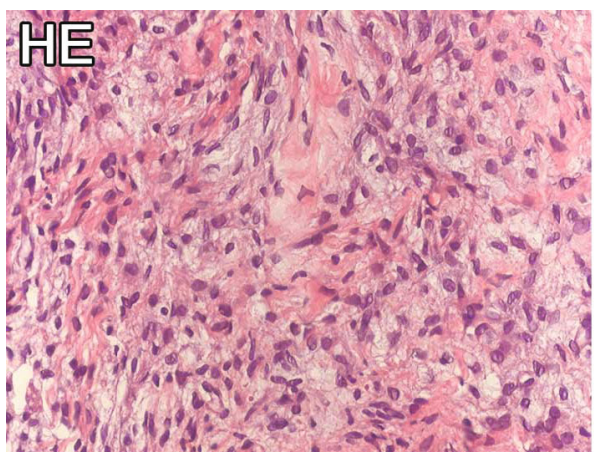

(c)

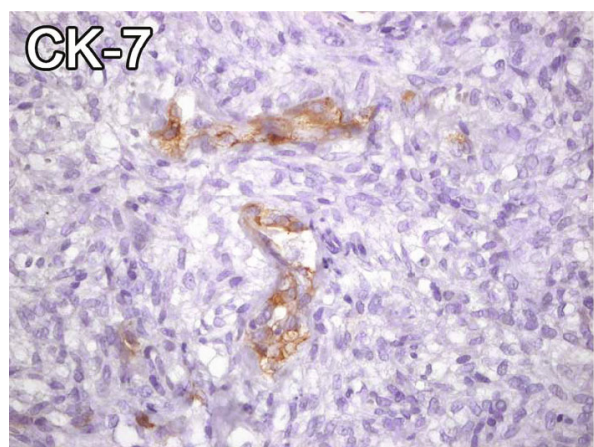

(e)

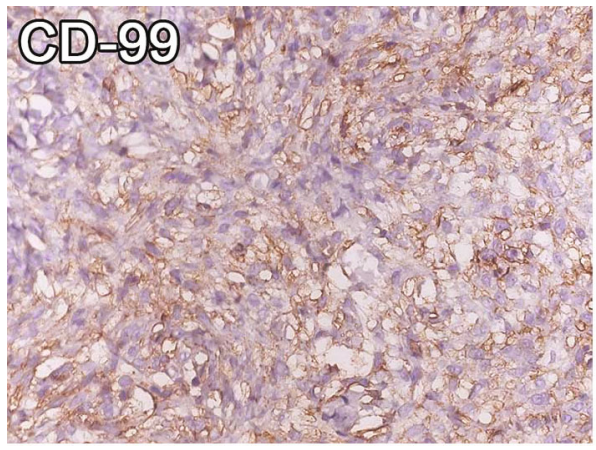

(g)

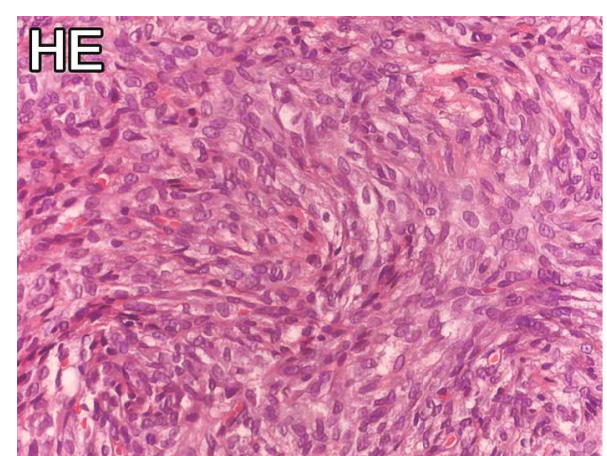

(b)

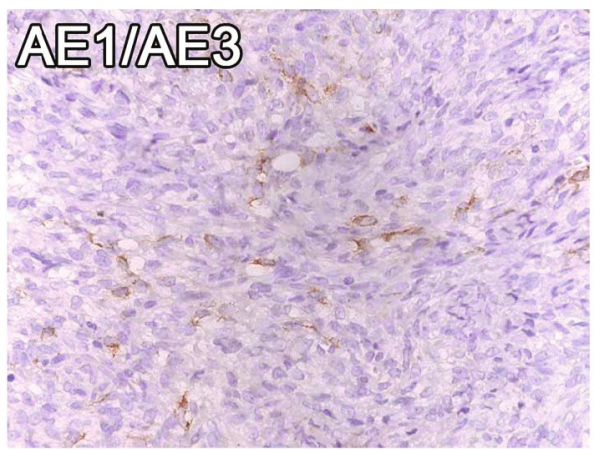

(d)

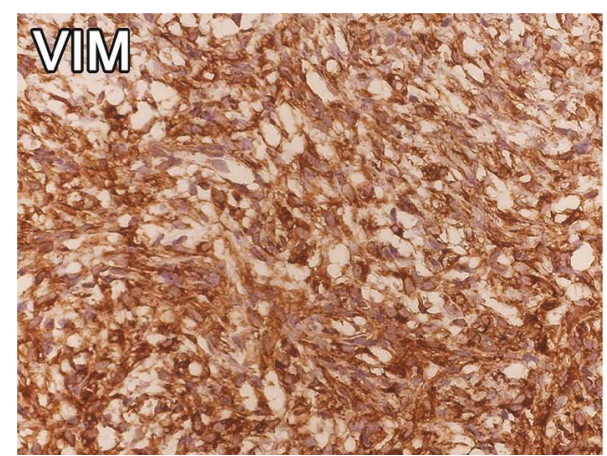

(f)

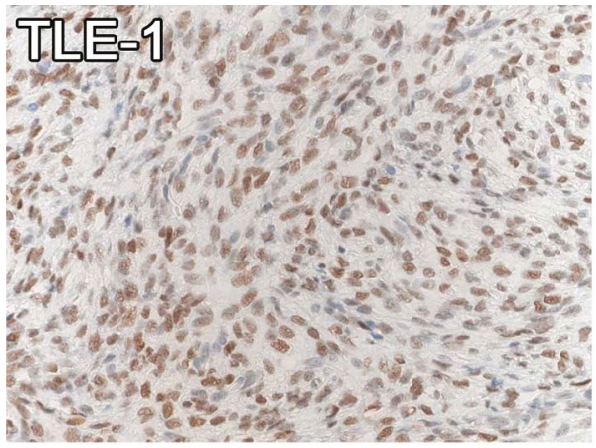

(h)

Figure 2: Continued. 


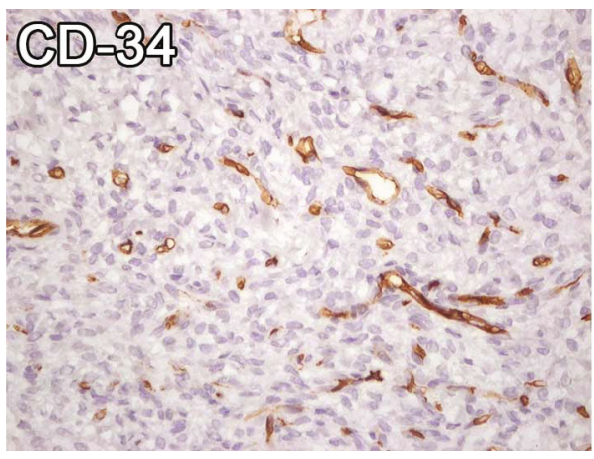

(i)

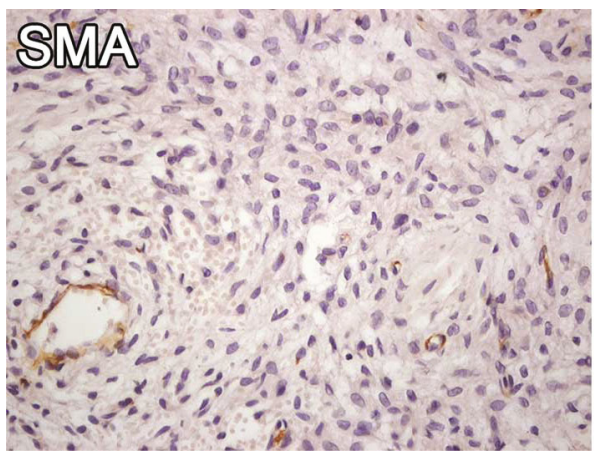

$(\mathrm{k})$

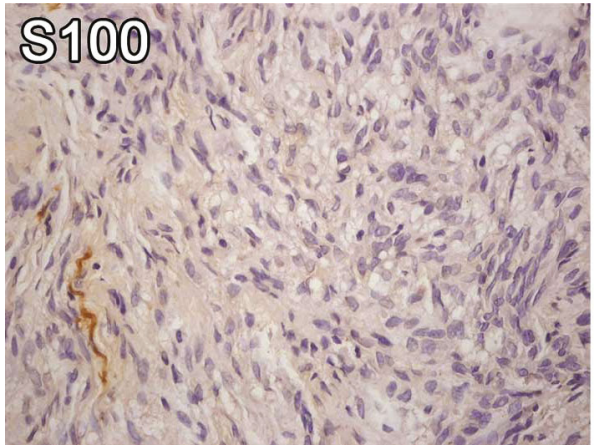

(j)

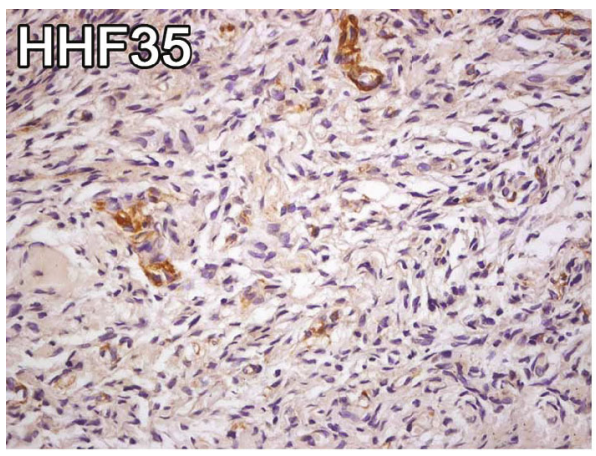

(1)

FIGURE 2: HE staining revealed a neoplasm composed of sheets of spindle cells arranged in bundles and exhibiting a storiform pattern (a, b). Hyalinized collagen and myxoid areas were identified in some parts of the specimen (c). The neoplastic cells were positive for AE1/AE3 (d), CK-7 (e), and CD99 (g); diffusely positive for vimentin (f) and TLE-1 (h); and negative for CD34 (i), S100 (j), SMA (k), and HHF35 (l). Scale bar: $\mathrm{A}=200 \mu \mathrm{m}$ and $\mathrm{B}-\mathrm{L}=50 \mu \mathrm{m}$.

\section{Case Report}

A 22-year-old male attended the dental emergency service in Palmas (Tocantins, Brazil), reporting pain in the region of the left mandibular body and ramus, which he believed to be related to an unerupted third molar. A panoramic radiographic exam showed the presence of an expansive and multilocular radiolucent lesion, extending from the left condyle to the mandibular body (Figure 1(a)). Computed tomography revealed a hypodense area with cortical bone destruction (Figures 1(b)-1(e)).

The patient was referred to a specialized dental service for evaluation and treatment. In the intraoral examination, an expansion of the cortical bone was noticed in the vestibular and lingual regions of the left mandible. An incisional biopsy was performed, and, during this surgical procedure, a solid, purple-colored lesion with hard consistency was detected near to the cortical bone, while a soft consistency lesion was noticed in the cancellous bone region. The clinic diagnostic hypotheses were ameloblastoma or malignant neoplasm.

The collected material was fixed in $10 \%$ buffered formalin. Paraffin sections were prepared for light microscopy using routine procedures. The sections were stained with hematoxylin and eosin (HE). Microscopic evaluation revealed a hypercellular tumor characterized by a sheet of spindle cells arranged in bundles, exhibiting sometimes a storiform pattern. Individually, the cells showed no defined limits with oval nuclei and loose chromatin (Figures 2(a) and 2(b)). Mitoses or necrosis was not observed throughout the specimen. Tumor stroma was scarce and well vascularized. In focal areas, hyalinized collagen and myxoid areas were identified (Figure 2(c)). Based on microscopic features, a provided diagnosis of sarcoma was made and an immunohistochemistry panel containing vimentin, AE1/AE3, S100, CD-34, CD-99, smooth muscle actin (SMA), and HHF35 was requested. The results showed that neoplastic cells were positive for vimentin and CD-99 (Figures 2(f) and 2(g), respectively). In focal areas of the tumor, the cells were positive for AE1/AE3 (Figure 2(d)), while SMA and HHF35 staining was negative for tumor cells (Figures 2(k) and 2(l), respectively). The positivity for AE1/AE3, in focal areas, leads us to perform additional immunostains for cytokeratin-7 (CK-7) and transducing-like enhancer of split 1 (TLE-1). The tumoral cells showed focal expression of CK7 (Figure 2(e)). TLE-1 was detected in nuclei of almost all tumoral cells (Figure 2(h)). Taken together, these results rendered the diagnosis of monophasic SS.

The patient was referred to the Head and Neck Medical Service for evaluation and treatment. The patient was submitted to computed tomography of the chest and abdomen and bone scintigraphy. These exams did not reveal any other tumor foci in the body of the patient, and the final diagnosis was a primary SS of the mandible. 


\section{Discussion}

Primary intraosseous SS is a rare neoplasm that can arise in the jaws. The cases of SS reported in the literature, in these particular anatomic sites, were commonly detected in young female patients, with the mandible and maxilla being equally affected by SS [29]. In the present manuscript, we reported a new case of primary intraosseous SS exhibiting a monophasic histologic type in the mandible of a young male patient.

SS can be classified histologically as biphasic, monophasic, and poorly differentiated. Biphasic SS is commonly characterized by the presence of glandular structures lined by well-differentiated cuboidal to columnar epithelium, which is surrounded by fibroblast-like spindle cells. Monophasic SS is marked by spindle cells arranged in fascicles exhibiting an ill-defined cytoplasm in a variably collagenous stroma. Poorly differentiated SS is characterized by sheets of uniform, closely packed, rounded cells [30, 31].

This malignant neoplasm contains a translocation $\mathrm{t}(\mathrm{X}$; 18)(SS18-SSX1-2), which can be detected by some molecular techniques such as fluorescence in situ hybridization [32-34]. The identification of this translocation has been claimed as the gold standard for the diagnosis of SS. Unfortunately, this exam is not always available in laboratories specialized in oral pathology and/or affordable for the patients. In this scenario, an adequate immunohistochemistry panel can be helpful for the diagnosis of this tumor.

In the present case report, the first microscopic impression of the tumor, associated with radiographic aspects, suggested that this neoplasm could be a sarcoma, thus eliminating the possibility of odontogenic tumors, such as odontogenic fibroma, ameloblastic fibroma, and ameloblastic fibrosarcoma. Immunohistochemistry analysis revealed that tumor cells were diffusely positive for vimentin and TLE-1, with scattered cells positive for keratin, especially CK-7, and negative for S100, CD-34, SMA, and HHF35. This panel of antibodies was important to exclude other sarcomas. Thus, the fact that neoplastic cells were negative for specific markers was fundamental for the exclusion of neoplasms derived from nervous (S100), endothelial (CD-34), and muscle tissues (SMA and HHF35). On the other hand, the presence of vimentin and keratin could represent a carcinosarcoma, excluding other malignant spindle cell neoplasms. The positivity for TLE-1, however, provides strong evidence in favor of the diagnosis of SS.

TLE-1 is a member of a large family of proteins that act as corepressor for many transcription factors and plays an essential role in osteogenesis, hematopoiesis, myogenesis, neuronal differentiation, and terminal epithelial differentiation [35-39]. TLE proteins are also effectors of several signaling pathways that control cell fate, such as Notch, Wnt/ $\beta$-catenin, and NF- $\kappa \mathrm{B}$ [39-41]. Therefore, the overexpression of these proteins is associated with tumorigenesis in several neoplasms. In SS, TLE-1 can modulate the Wnt/ $\beta$ catenin expression, a well-known signaling pathway involved with the development of this tumor [42-44].

El Beaino et al. in their systematic review and metaanalysis regarding the diagnostic value of TLE-1 in SS highlighted this protein as a legitimate biomarker for SS [45].
Despite the fact that hybridization analysis for the chromosomal $t(X ; 18)$ translocation was considered the most relevant exam for the diagnosis of SS, the pathologist, however, must be aware that diagnosis of SS should be also based on clinical context, histologic features, and immunohistochemistry profile [11], once some tumors can exhibit other types of genetic mutations [45-48]. Indeed, molecular testing is not required if the diagnosis of SS was certain or probable on the basis of clinical, histologic, and immunohistochemical evaluation [49].

As described above, the monophasic pattern of SS is very a challenging diagnosis especially in oral pathology, where this tumor is very rare. In our case, the association of clinical history, microscopic morphology features, and immunohistochemistry profile leads us to the final diagnosis of SS.

SS has an aggressive behavior, and, for this reason, wide surgical excision, to obtain clear margins, followed by adjuvant radio and/or chemotherapy, is the recommended treatment modality $[50,51]$. Primary intraosseous SS of the jaws has a high incidence of local recurrence and tumor-related death [29]. Thus, long-term follow-up is necessary and important for early detection of recurrence. In our reported case, the patient has been followed up for the last two years with no sign of the disease.

\section{Ethical Approval}

This work was approved by the Ethics Research Committee of the ITPAC (Instituto Tocantinense Presidente Antônio Carlos) S.A. in Araguaina, Tocantins, Brazil, under the number CAAE 99151718.9.0000.0014.

\section{Conflicts of Interest}

The authors state that there are no conflicts of interest to disclose.

\section{Acknowledgments}

The authors would like to thank Nadir Freitas and Mabiliane Albuquerque for their helpful technical assistance.

\section{References}

[1] C. Fisher, "Synovial sarcoma," Annals of Diagnostic Pathology, vol. 2, no. 6, pp. 401-421, 1998.

[2] S. W. Weiss and J. R. Goldblum, "Malignant soft tissue tumors of uncertain type," in Enzinger and Weiss's Soft Tissue Tumors, pp. 1483-1509, Mosby Inc., St Louis, 4th edition, 2001.

[3] H. J. Siegel, W. Sessions, and M. A. Casillas, "Synovial sarcoma: clinicopathologic features, treatment, and prognosis," Orthopedics, vol. 30, no. 12, pp. 1020-1025, 2007.

[4] L. C. Knox, "Synovial Sarcoma," American Journal of Cancer Research, vol. 28, no. 3, pp. 461-480, 1936.

[5] R. Carrillo, J. L. Rodriguez-Peralto, and J. G. Batsakis, "Synovial sarcomas of the head and neck," The Annals of Otology, Rhinology, and Laryngology, vol. 101, no. 4, pp. 367-370, 1992.

[6] S. K. Machen, K. A. Easley, and J. R. Goldblum, "Synovial sarcoma of the extremities: a clinicopathologic study of 34 cases, including semi-quantitative analysis of spindled, epithelial, 
and poorly differentiated areas," The American Journal of Surgical Pathology, vol. 23, no. 3, pp. 268-275, 1999.

[7] E. M. Sturgis and B. O. Potter, "Sarcomas of the head and neck region," Current Opinion in Oncology, vol. 15, no. 3, pp. 239252, 2003.

[8] F. de Logu, F. Ugolini, C. Caporalini et al., "TRPA1 expression in synovial sarcoma may support neural origin," Biomolecules, vol. 10, no. 10, p. 1446, 2020.

[9] C. Fisher, "Synovial sarcoma: ultrastructural and immunohistochemical features of epithelial differentiation in monophasic and biphasic tumors," Human Pathology, vol. 17, no. 10, pp. 996-1008, 1986.

[10] L. Guillou, J. Benhattar, F. Bonichon et al., "Histologic grade, but not SYT-SSX fusion type, is an important prognostic factor in patients with synovial sarcoma: a multicenter, retrospective analysis," Journal of Clinical Oncology, vol. 22, no. 20, pp. 4040-4050, 2004.

[11] M. El Beaino, D. M. Araujo, A. J. Lazar, and P. P. Lin, "Synovial sarcoma: advances in diagnosis and treatment identification of new biologic targets to improve multimodal therapy," Annals of Surgical Oncology, vol. 24, no. 8, pp. 2145-2154, 2017.

[12] F. R. Amble, K. D. Olsen, A. G. Nascimento, and R. L. Foote, "Head and neck synovial cell sarcoma," Otolaryngology and Head and Neck Surgery, vol. 107, no. 5, pp. 631-637, 1992.

[13] W. J. Harb, M. A. Luna, S. R. Patel, M. T. Ballo, D. B. Roberts, and E. M. Sturgis, "Survival in patients with synovial sarcoma of the head and neck: association with tumor location, size, and extension," Head \& Neck, vol. 29, no. 8, pp. 731-740, 2007.

[14] W. Al-Daraji, J. Lasota, R. Foss, and M. Miettinen, "Synovial sarcoma involving the head," The American Journal of Surgical Pathology, vol. 33, no. 10, pp. 1494-1503, 2009.

[15] A. P. Dei Tos, P. Dal Cin, R. Sciot et al., "Synovial sarcoma of the larynx and hypopharynx," The Annals of Otology, Rhinology, and Laryngology, vol. 107, no. 12, pp. 1080-1085, 1998.

[16] M. Mir-Abedy, "Considerations on the base of the tongue and its tumors. (Apropos of a case of synoviosarcoma and a case of neurofibroma)," Les Annales d'Oto-Laryngologie, vol. 79, pp. 547-561, 1962.

[17] C. Komis, G. A. Lagogiannis, G. Faratzis, and A. D. Rapidis, "Synovial sarcoma of the tongue: report of a case and review of the literature," Journal of Oral and Maxillofacial Surgery, vol. 66, no. 1, pp. 154-160, 2008.

[18] M. de Almeida-Lawall, A. Mosqueda-Taylor, R. E. BolognaMolina et al., "Synovial sarcoma of the tongue: case report and review of the literature," Journal of Oral and Maxillofacial Surgery, vol. 67, no. 4, pp. 914-920, 2009.

[19] L. E. Basile, B. Hoch, and J. K. Dillon, "Synovial sarcoma of the tongue: report of a case," Journal of Oral and Maxillofacial Surgery, vol. 74, no. 1, pp. 95-103, 2016.

[20] V. C. de Araújo and D. C. Monteiro, "Oral synovial sarcoma: report of a case," Journal of Oral and Maxillofacial Surgery, vol. 47, no. 9, pp. 1001-1003, 1989.

[21] K. T. Mahesh, I. A. Ponnuswamy, M. P. David, P. Shivhare, M. I. Puttaranganayak, and P. Sinha, "Synovial sarcoma of the buccal mucosa: a rare case report," Case Reports in Dentistry, vol. 2013, Article ID 938291, 5 pages, 2013.

[22] G. Massarelli, F. Tanda, and B. Salis, "Syhovial sarcoma of the soft palate: report of a case," Human Pathology, vol. 9, no. 3, pp. 341-345, 1978.

[23] A. Ferlito, N. Gale, A. Hvala, and A. Masera, "Synovial sarcoma of the soft palate in a child: a light and electron micro- scopic study," The Journal of Laryngology and Otology, vol. 95, no. 2, pp. 197-204, 1981.

[24] A. Doubi, M. Doubi, N. Alzaher, and A. Tulbah, "Synovial sarcoma of the hard palate: the third case in the medical literature," Hematology/Oncology and Stem Cell Therapy, vol. 12, no. 1, pp. 60-63, 2019.

[25] G. V. Rao, T. Sravya, Y. Sivaranjani, and V. R. Bhat, "Primary biphasic synovial sarcoma of gingiva: report of a rare case," Journal of Oral and Maxillofacial Pathology, vol. 18, no. 1, pp. 77-80, 2014.

[26] S. Meer, H. Coleman, and M. Altini, "Oral synovial sarcoma: a report of 2 cases and a review of the literature," Oral Surgery, Oral Medicine, Oral Pathology, Oral Radiology, and Endodontics, vol. 96, no. 3, pp. 306-315, 2003.

[27] Y. Monzen, N. Hirai, T. Nishisaka, and K. Hayashi, "MR imaging of synovial sarcoma arising from the floor of the mouth: a case report," Radiation Medicine, vol. 19, no. 1, pp. 47-50, 2001.

[28] Y. Wang, F. Zhu, and K. Wang, "Synovial sarcoma of the floor of the mouth: a rare case report," BMC Oral Health, vol. 20, no. 1, p. 5, 2020.

[29] Z. Liu, S. Jin, S. Fu, Y. Hu, and Y. He, "Management of the primary intraosseous synovial sarcoma of the jaws: be careful of the surgical margin," Journal of Oral and Maxillofacial Surgery, vol. 73, no. 3, pp. 550-563, 2015.

[30] C. D. M. Fletcher, “Tumors of soft tissue," in Diagnostic Histopathology of Tumors, C. D. M. Fletcher, Ed., pp. 1796-1870, Elsevier Saunders, 2013.

[31] J. R. Goldblum, A. L. Folpe, and S. W. Weiss, "Malignant soft tissue tumors of uncertain type," in Enzinger and Weiss's Soft Tissue Tumors, J. R. Goldblum, A. L. Folpe, and S. W. Weiss, Eds., pp. 1028-1112, Elsevier Saunders, 2014.

[32] K. Nagao, H. Ito, and H. Yoshida, "Chromosomal translocation $\mathrm{t}(\mathrm{X} ; 18)$ in human synovial sarcomas analyzed by fluorescence in situ hybridization using paraffin-embedded tissue," The American Journal of Pathology, vol. 148, no. 2, pp. 601609, 1996.

[33] M. F. Amary, F. Berisha, F. D. C. Bernardi et al., "Detection of SS18-SSX fusion transcripts in formalin-fixed paraffinembedded neoplasms: analysis of conventional RT-PCR, qRT-PCR and dual color FISH as diagnostic tools for synovial sarcoma," Modern Pathology, vol. 20, no. 4, pp. 482496, 2007.

[34] K. B. Jones, J. J. Barrott, M. Xie et al., "The impact of chromosomal translocation locus and fusion oncogene coding sequence in synovial sarcomagenesis," Oncogene, vol. 35, no. 38, pp. 5021-5032, 2016.

[35] M. Agarwal, P. Kumar, and S. J. Mathew, "The Groucho/ Transducin-like enhancer of split protein family in animal development," Life, vol. 71, p. 1824, 2019.

[36] G. Chen and A. J. Courey, "Groucho/TLE family proteins and transcriptional repression," Gene, vol. 249, no. 1-2, pp. 1-16, 2000.

[37] M. Gasperowicz and F. Otto, "Mammalian Groucho homologs: redundancy or specificity?," Journal of Cellular Biochemistry, vol. 95, no. 4, pp. 670-687, 2005.

[38] S. Stifani, C. M. Blaumueller, N. J. Redhead, R. E. Hill, and S. Artavanis-Tsakonas, "Human homologs of a _Drosophila Enhancer of split_ gene product define a novel family of nuclear proteins," Nature Genetics, vol. 2, no. 2, pp. 119-127, 1992. 
[39] Y. Liu, G. Dehni, K. J. Purcell et al., "Epithelial expression and chromosomal location of human _TLE_ genes: implications for Notch signaling and neoplasia," Genomics, vol. 31, no. 1, pp. 58-64, 1996.

[40] A. Kaul, E. Schuster, and B. H. Jennings, "The Groucho corepressor is primarily recruited to local target sites in active chromatin to attenuate transcription," PLoS Genetics, vol. 10, no. 8, article e1004595, 2014.

[41] S. Ramasamy, B. Saez, S. Mukhopadhyay et al., "Tle1 tumor suppressor negatively regulates inflammation in vivo and modulates NF- $\kappa \mathrm{B}$ inflammatory pathway," Proceedings of the National Academy of Sciences of the United States of America, vol. 113, no. 7, pp. 1871-1876, 2016.

[42] K. Baird, S. Davis, C. R. Antonescu et al., "Gene expression profiling of human sarcomas: insights into sarcoma biology," Cancer Research, vol. 65, no. 20, pp. 9226-9235, 2005.

[43] D. Pretto, R. Barco, J. Rivera, N. Neel, M. D. Gustavson, and J. E. Eid, "The synovial sarcoma translocation protein SYTSSX2 recruits _ $\beta_{-}$-catenin to the nucleus and associates with it in an active complex," Oncogene, vol. 25, no. 26, pp. 36613669, 2006.

[44] F. Bozzi, A. Ferrari, T. Negri et al., "Molecular characterization of synovial sarcoma in children and adolescents: evidence of akt activation," Translational Oncology, vol. 1, no. 2, pp. 95101, 2008.

[45] M. el Beaino, D. C. Jupiter, T. Assi et al., "Diagnostic Value of TLE1 in Synovial Sarcoma: A Systematic Review and MetaAnalysis," Sarcoma, vol. 2020, Article ID 7192347, 6 pages, 2020.

[46] A. A. Sandberg and J. A. Bridge, "Updates on the cytogenetics and molecular genetics of bone and soft tissue tumors. Synovial sarcoma," Cancer genetics and cytogenetics, vol. 133, no. 1, pp. 1-23, 2002.

[47] J. Przybyl, R. Sciot, P. Rutkowski et al., "Recurrent and novel SS18-SSX fusion transcripts in synovial sarcoma: description of three new cases," Tumour Biology, vol. 33, no. 6, pp. 2245-2253, 2012.

[48] C. T. Storlazzi, F. Mertens, N. Mandahl et al., "A novel fusion gene, SS18L1/SSX1, in synovial sarcoma," Genes, Chromosomes \& Cancer, vol. 37, no. 2, pp. 195-200, 2003.

[49] J. M. Coindre, M. Pelmus, I. Hostein, C. Lussan, B. N. Bui, and L. Guillou, "Should molecular testing be required for diagnosing synovial sarcoma?," Cancer, vol. 98, no. 12, pp. 2700-2707, 2003.

[50] P. Bergh, J. M. Meis-Kindblom, F. Gherlinzoni et al., "Synovial sarcoma: identification of low and high risk groups," Cancer, vol. 85, no. 12, pp. 2596-2607, 1999.

[51] A. Wushou and X. C. Miao, "Tumor size predicts prognosis of head and neck synovial cell sarcoma," Oncology Letters, vol. 9, no. 1, pp. 381-386, 2015. 